\title{
Culture independent molecular analysis of bacterial communities in the mangrove sediment of Sundarban, India
}

\author{
Abhrajyoti Ghosh ${ }^{1,3+}$, Nirmalya Dey ${ }^{1,4+}$, Amit Bera ${ }^{1}$, Amit Tiwari ${ }^{1,5}$, KB Sathyaniranjan ${ }^{1}$, Kalyan Chakrabarti ${ }^{2}$, \\ Dhrubajyoti Chattopadhyay ${ }^{1 *}$
}

\begin{abstract}
Background: Sundarban is the world's largest coastal sediment comprising of mangrove forest which covers about one million hectares in the south-eastern parts of India and southern parts of Bangladesh. The microbial diversity in this sediment is largely unknown till date. In the present study an attempt has been made to understand the microbial diversity in this sediment using a cultivation-independent molecular approach.

Results: Two $16 \mathrm{~S}$ rRNA gene libraries were constructed and partial sequencing of the selected clones was carried out to identify bacterial strains present in the sediment. Phylogenetic analysis of partially sequenced $16 \mathrm{~S}$ rRNA gene sequences revealed the diversity of bacterial strains in the Sundarban sediment. At least 8 different bacterial phyla were detected. The major divisions of detected bacterial phyla were Proteobacteria (alpha, beta, gamma, and delta), Flexibacteria (CFB group), Actinobacteria, Acidobacteria, Chloroflexi, Firmicutes, Planctomycetes and Gammatimonadates.

Conclusion: The gammaproteobacteria were found to be the most abundant bacterial group in Sundarban sediment. Many clones showed similarity with previously reported bacterial lineages recovered from various marine sediments. The present study indicates a probable hydrocarbon and oil contamination in this sediment. In the present study, a number of clones were identified that have shown similarity with bacterial clones or isolates responsible for the maintenance of the S-cycle in the saline environment.
\end{abstract}

\section{Background}

The majority $(60-70 \%)$ of the world tropical and subtropical coastlines are covered with mangrove ecosystems. Mangroves are known to be highly productive ecosystems and have immense ecological values. They protect and stabilize the costal zones, nourish and nurture the coastal water with nutrients. They play important role as the feeding and breeding areas of many organisms including plants, animals and micro-organisms. The microbial community in the mangrove sediment is strongly influenced by bio-geographical, anthropological and ecological properties. These properties include food web in the ecosystem, nutrient cycling and the presence of organic and inorganic matters.

\footnotetext{
* Correspondence: dhrubajyotic@gmail.com

† Contributed equally

'Department of Biochemistry and Department of Biotechnology, University

of Calcutta, 35, Ballygunge Circular Road, Kolkata- 700019, West Bengal, India
}

During the past decade, the development of molecular techniques using nucleic acids has led to many new findings in the studies of microbial ecology [1]. As a basic approach to clarify the microbial communities, $16 \mathrm{~S}$ rRNA genes are amplified by PCR from nucleic acids extracted from environmental samples, and then the PCR products are cloned and sequenced. This approach can avoid the limitation of the traditional culturing techniques for assessing the microbial diversity in the natural environments.

Both the sediment and soil probably represent some of the most complex microbial habitats on the Earth. There may be several thousand species of bacteria in 1 $\mathrm{g}$ of soil [2]. To study the genetic diversity and to analyse the members of mixed microbial populations are the two most important steps in microbial community studies. However, little research has been done on 
microbial diversity in marine sediments, and little information is currently available [3].

Mangrove ecosystems are in general nutrient-deficient, especially of nitrogen and phosphorus [4-8]. In spite of this, mangroves are highly productive. Microbial activity is responsible for major nutrient transformations within a mangrove ecosystem $[4,9]$. In tropical mangroves, bacteria and fungi constitute $91 \%$ of the total microbial biomass, whereas algae and protozoa represent only $7 \%$ and $2 \%$, respectively [10]. Bacteria are responsible for most of the carbon flux in tropical mangrove sediments. They process most of the energy flow and nutrients, and act as a carbon sink. For example, in semiarid mangrove ecosystems on the Indus river in Pakistan, bacteria were attached to the sediment particles and processed most of the ecosystem nutrients [11].

Several studies have shown the uniqueness of mangrove sediments with respect to their microbial composition [3,11-15]. Studies on microbial diversity in the mangrove sediments are important to understand the process of biogeochemical cycling and pollutants removal [16].

Sundarban is world's largest coastal wetland comprising of mangrove forest which covers about one million hectares in the delta of the rivers Ganga, Bramhaputra, and Meghna [17]. This mangrove region is shared between Bangladesh $(\sim 60 \%)$ and India $(\sim 40 \%)$. The area experiences a subtropical monsoon climate with the annual rainfall of about $1600-1800 \mathrm{~mm}$ and several cyclonic storms. The dynamics of this region is mainly maintained by sedimentations from all the three major rivers. Both the spatial and temporal influences have been demonstrated on the salinity in this region. The biodiversity of Sundarban includes numerous species of phytoplankton, zooplankton, micro-organisms, benthic invertebrates, molluscs, amphibians and mammals [17]. About 350 species of vascular plants, 250 species of fishes, and 300 species of birds are reported in Sundarban region [17]. Little work has been carried out on the microbial diversity in the Sundarban sediments.

This paper describes the culture independent microbial diversity analysis of the sediment sample from one of the famous islands of Sundarban, Netidhopani. Our molecular phylogenetic analysis reveals the occurrence of the bacterial 16S rRNA gene sequences that are unique and sequences that are previously reported in other mangrove sediments. Microbial community structure analysis can provide a better understanding about the microbial population and their interactions in a defined geographical region. Moreover such data are important with respect to our understanding of mangrove ecosystem processes and the role of micro-organisms in maintaining these processes [18].
The present results considerably extend our understanding on microbial diversity in Sundarban sediments. Furthermore, these results will open a new door towards understanding microbial diversity in the largest mangrove sediment in the world.

\section{Methods}

\section{Site Selection}

Sediment samples were collected between $1^{\text {st }}$ to $10^{\text {th }}$ November' 2006 from one of the composite islands of

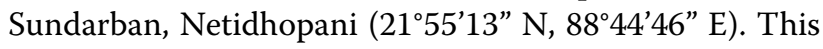
area is inundated with sea water about every twelve hours. Soil was collected after recessation when the land was exposed. This soil was highly saline with $\mathrm{Ec}_{\mathrm{e}} 12.6 \mathrm{dSm}^{-1}$.

\section{Soil Sampling, Analyses, and Site Climate}

Soil samples were collected from the top $15 \mathrm{~cm}$ of the five different sites on the island and brought to the laboratory in properly labelled, autoclaved, and sealed polythene bags on ice. All the soil analyses were carried out in the Department of Biotechnology, University of Calcutta. Microbiological and biochemical analyses were performed with the field moist soils. Physico-chemical analysis was carried out with air-dried soil samples. The soil $\mathrm{pH}$ was measured in 1:2.5 soil water suspensions. The $\mathrm{Ec}_{\mathrm{e}}$ and ionic composition of soil saturation extract were measured following the method described in United States Department of Agriculture (USDA), 1954 [19]. The organic C (OC) and total N (TN) were measured by the methods proposed by Nelson \& Sommers 1982 and Black, $1965[4,20]$ respectively. Textural composition (i.e., determination of sand, silt and clay) was determined by International Pipette Method as described previously [21]. The soil sample contained around $53.5 \%$ sand, $23.32 \%$ silt, $28 \%$ clay, $4.3 \%$ organic matter, and $0.395 \%$ total $\mathrm{N}$ (Average values of the triplicate analysis). The soil $\mathrm{pH}$ was found to be alkaline and it was 8.1. Prior to the total DNA isolation, all the soil samples (five samples were collected from different sites of the island) were mixed to homogeneity to make a single composite sample for DNA isolation.

\section{Isolation of total soil DNA}

Total soil (sediment) DNA was isolated using a modified CTAB-SDS based DNA extraction technique [22]. Soil sample of $5 \mathrm{~g}$ was mixed with $13.5 \mathrm{ml}$ of the DNA extraction buffer [100 mM Tris- $\mathrm{HCl}(\mathrm{pH} 8.0), 100 \mathrm{mM}$ sodium-EDTA (pH 8.0), $100 \mathrm{mM}$ sodium phosphate buffer (pH 8.0), $1.5 \mathrm{M} \mathrm{NaCl}, 1 \% \mathrm{CTAB}$ ] and $100 \mu \mathrm{l}$ of proteinase $\mathrm{K}(10 \mathrm{mg} / \mathrm{ml})$ in oakridge tube by horizontal shaking at $200 \mathrm{rpm}$ for $30 \mathrm{~min}$ at $37^{\circ} \mathrm{C}$. After the shaking treatment, $1.5 \mathrm{ml}$ of $20 \%$ SDS was added, and then the sample was incubated at $65^{\circ} \mathrm{C}$ water bath for two hours with gentle end-over-end inversions every 15-20 min. The 
supernatant was collected after centrifugation at $6000 \times \mathrm{g}$ for $10 \mathrm{~min}$ at room temperature into $50 \mathrm{ml}$ centrifuge tube. The soil pellet was extracted two more times by adding $4.5 \mathrm{ml}$ of the extraction buffer and $0.5 \mathrm{ml}$ of $20 \%$ SDS; vortexing for $10 \mathrm{~s}$, incubating at $65^{\circ} \mathrm{C}$ for $10 \mathrm{~min}$, and centrifuging as before. Supernatants from three cycles of extractions were combined and mixed with an equal volume of chloroform-isoamyl alcohol (24:1 v/v). The aqueous phase was recovered by centrifugation and total nucleic acid was precipitated with 0.6 volume of isopropanol at room temperature for $1 \mathrm{~h}$. The pellet of crude nucleic acid was obtained by centrifugation at $16,000 \times \mathrm{g}$ for $20 \mathrm{~min}$ at room temperature, washed twice with cold $70 \%$ ethanol, and resuspended in sterile deionised water to give a final volume of $250 \mu \mathrm{l}$. RNase $(10 \mathrm{mg} / \mathrm{ml})$ treatment followed by phenol extraction and the re-precipitation was carried out prior to PCR amplification of $16 \mathrm{~S}$ rRNA gene sequences.

\section{PCR amplification and partial 16S rRNA gene library construction}

Partial amplification of the $16 \mathrm{~S}$ rRNA gene was performed with the thermal cycler ABI 2700 (ABI, Foster City, USA). The PCR of the $16 \mathrm{~S}$ rRNA gene sequence from the total soil DNA was conducted in a final volume of $50 \mu \mathrm{l}$. The reaction mixture included 20-50 ng of isolated total soil DNA, $2 \mathrm{U}$ taq polymerase (Recombinant, Cat. No. SKU\# 10342-020, Invitrogen, Germany), $1 \times$ PCR buffer with $1.5 \mathrm{mM} \mathrm{MgCl}_{2}, 200$ $\mathrm{mM}$ each dNTP, and $10 \mathrm{pmol}$ of each primer (IDT, USA). The primers were chosen to amplify a 977-bp segment of $16 \mathrm{~S}$ rRNA gene spanning V3-V9 region to construct the first library. In the first library (D16S_pMOS library) construction, forward primer used was 515F (5'-3') GTGCCAGCAGCCGCGGTAA and the reverse primer was 1492R (5'-3') TACGGYTACCTTGTTACGACTT [23]. This pair of primers was chosen to amplify both the bacterial and archaeal $16 S$ rRNA gene sequences in the total soil DNA. Before amplification cycle DNA was denatured for 2 min at $94^{\circ} \mathrm{C}$ and after amplification an extension step $\left(7 \mathrm{~min}\right.$ at $72^{\circ} \mathrm{C}$ ) was performed. The cycling parameters consisted of 28 cycles at: denaturation at $94^{\circ} \mathrm{C}$ for $30 \mathrm{sec}$, primer annealing at $45^{\circ} \mathrm{C}$ for $1 \mathrm{~min}$, extension at $72^{\circ} \mathrm{C}$ for $1 \mathrm{~min}$. The samples were held at $4^{\circ} \mathrm{C}$ until separated electrophoretically in a $2 \%$ agarose gel in $0.5 \times$ Tris-Borate-EDTA buffers and visualized using ethidium bromide under ultraviolet illumination. All the amplified PCR products were agarose-gel-eluted using Qiagen gel elution kit.

Since the proteobacterial population has previously been reported to be quite abundant in other saline sediments [3,24-26] a second library was also constructed using the proteobacteria specific universal SSU primer set [27], uni-forward (5'-3') TGCCAGCAGCCGCGGTA and uni-reverse (5'-3') GACGGGCGGTGTGTACAA, to screen for proteobacterial population in Sundarban sediments. The amplification cycle was as follows; initial denaturation for 5 min at $94^{\circ} \mathrm{C}$, followed by 35 cycles at: $30 \mathrm{sec}$ denaturation at $94^{\circ} \mathrm{C}, 1 \mathrm{~min}$ for primer annealing at $50^{\circ} \mathrm{C}$, and 1 min of extension at $72^{\circ} \mathrm{C}$. After the amplification a final extension step $\left(7 \mathrm{~min}\right.$ at $\left.72^{\circ} \mathrm{C}\right)$ was performed. The samples were held at $4^{\circ} \mathrm{C}$ until analysis by agarose gel electrophoresis followed by elution using the Qiagen gel elution kit.

Two partial 16S rRNA gene libraries were constructed using gel eluted amplified PCR products (515F/1492R amplicon and uni-for/uni-rev amplicon) and pMOSBlue vector (Pharmacia). The gel eluted PCR products were ligated to pMOS-Blue vector and then transformed into competent Escherichia coli XL1-Blue. The clones were screened for $\alpha$-complementation by using X-Gal (5-bromo-4-chloro-3-indolyl- $\beta$-D-galactopyranoside) and IPTG (isopropyl- $\beta$-D thiogalactoside). All the positive clones were confirmed by PCR amplification and restriction digestion. All the positive clones were stored as glycerol stock at $-70^{\circ} \mathrm{C}$ freezer.

\section{Sequencing of the 16S rRNA gene Fragment}

The sequencing of the partial 16S rRNA gene fragments in each of the recombinant plasmids was performed in ABI Prism 3100 automated DNA sequencer (Applied Biosystem, Foster City, California, USA) with the single primer 515F for D16S_pMOS library and uni-for for DUni_pMOS library, respectively. The sequencing reaction was performed using 5 pmoles $515 \mathrm{~F} /$ uni-for primer and the Big Dye Terminator V3.1 sequencing kit as per manufacturer's protocol. The sequencing reaction conditions were as follows: $96^{\circ} \mathrm{C}$ for $10 \mathrm{sec}, 50^{\circ} \mathrm{C}$ for $10 \mathrm{sec}$, and $60^{\circ} \mathrm{C}$ for $4 \mathrm{~min}$ for 25 cycles. After the sequencing PCR, the products $(10 \mu \mathrm{l})$ were treated with $2 \mu \mathrm{l}$ of 125 mM Na-EDTA, $\mathrm{pH} 8.0$, and then precipitated using $2 \mu \mathrm{l}$ of $3 \mathrm{M} \mathrm{NaOAc}(\mathrm{pH} \mathrm{4.6)}$ and $50 \mu \mathrm{l}$ absolute ethanol for 20 minutes at room temperature. The DNA was recovered by centrifugation $\left(13,000 \mathrm{rpm}\right.$ for $30 \mathrm{~min}$ at $\left.20^{\circ} \mathrm{C}\right)$, washed with $70 \% \mathrm{EtOH}$, dried, and resuspended in $15 \mu \mathrm{l}$ Hi Di formamide (Applied Biosystems, Foster City, California, USA). Sequencing was performed in the ABI Prism 3100 Genetic Analyzer. Raw sequences were edited and assembled using the Auto Assembler program (V5.2). All the sequences were used to identify the bacteria with the help of the BLASTn program http://www. ncbi.nlm.nih.gov/BLAST, and all the sequences were 
submitted to GenBank. The multiple sequence alignment was performed using CLUSTAL-W software package http://www.ebi.ac.uk/Tools/clustalw2/index.html.

\section{Blast Search \& Phylogenetic Analysis}

The partial 16S rRNA gene sequences of the clones were compared with those available in the public databases. Identification to the species level was determined as a $16 \mathrm{~S}$ rRNA gene sequence similarity of $\geq 97 \%$ with that of the prototype strain sequence in the GenBank. Sequence alignment and comparison was performed using the multiple sequence alignment program CLUSTALX (v 1.83) [28], with default parameters and the data converted to PHYLIP format. Minor modifications in the alignment were made using the BIOEDIT sequence editor. Rooted and unrooted phylogenetic trees were constructed using neighbor-joining (NJ) method and the TREEVIEW program for display of phylogenetic relationship [29]. Bootstrap analysis was performed as described by Felsenstein in 1985 [30] on 1000 random samples taken from the multiple alignments; analysis was done using the ClustalX programs.

\section{Nucleotide sequence accession numbers}

The 16S rRNA gene sequences reported in this study was submitted to the GenBank database under accession numbers EU939923-EU939972 (D16S_pMOS library) and EU999048-EU999127 (Duni_pMOS library).

\section{Results and discussion}

\section{DNA extraction, Library construction and sequencing} analysis

The total DNA was extracted from the sediment of Netidhopani, Sundarban, using modified CTAB-SDS based DNA isolation technique. Two partial 16S rRNA gene clone libraries were established from the PCR amplified partial 16S rRNA gene sequences using $515 \mathrm{~F} / 1492 \mathrm{R}$ and uni-for/uni-rev primer sets, respectively. The recombinant clones in the libraries were selected based on $\alpha$-complementation (blue-white screening) technique and also confirmed by the rePCR analysis and restriction enzyme digestion. Our sequencing analysis included 85 clones from D16S_pMOS library and 110 clones from DUni_pMOS library. All the sequenced clones were screened for sequences that repeat more than once in the library. Our final analysis included 50 clones from D16S_pMOS library and 80 clones from DUni_pMOS library, respectively (Table1) (Figures 1, 2, 3 and 4). Methylophaga spp. was found to be abundant in both the libraries. We also found four non bacterial chloroplastic DNA in recombinant clones from the two libraries. Although, the primer pair 515F \& 1492R could amplify both bacterial and archaeal 16S rRNA gene sequences, we did not get any archaeal sequence in our library (D16S_pMOS). This was probably because of the limitation in our total DNA extraction protocol and low primer specificities towards the archaeal 16S rRNA gene sequences. Our phylogenetic analysis revealed that 130 bacterial clones (50 clones from D16S_pMOS library and 80 clones from DUni_pMOS library) fell into 8 major phyla of the bacterial domain: Proteobacteria (Alpha-, Beta-, Gamma-, and Delta-), the Cytophaga-Flexibacter-Bacteroides (CFB) group, Actinobacteria, Chloroflexi, Firmicutes, Gemmatimonadetes, Acidobacteria group, and Planctomycetes (Table 1).

\section{Proteobacteria}

A total of 86 clones represented by 29 sequence types from D16S_pMOS library and 57 sequence types from DUni_pMOS library were identified as proteobacterial in origin by sequencing analysis (Table 1) (Figure 3 ). Most of the proteobacterial sequence types from both the libraries were similar to previously described isolates or metagenomic clones from coastal marine sediments or waters [GenBank description, sequences that were submitted to GenBank but yet to be published in scientific journals]. In D16S_pMOS library 29 proteobacterial sequence types accounted for $58 \%$ of the gene library and in DUni_pMOS library 57 proteobacterial sequence types accounted for $71 \%$ of the gene library (Figure 1).

\section{Gammaproteobacteria}

The gammaproteobacteria represented the most abundant proteobacterial subdivision $(59 \%$ and $77 \%$ among the proteobacterial sequence types in D16S_pMOS and DUni_pMOS libraries, respectively) (Table 1). The most abundant sequence type in both the libraries showed similarity to Methylophaga, indicating a strong involvement of these bacterial species in the maintenance of the biogeochemical cycle in Sundarban sediment. A number of gammaproteobacterial sequence types showed similarity to organisms involved in the S-cycle (DUni_9, DUni_15, DUni_68, DUni_77, and DUni_91). A number of the gammaproteobacterial clones showed sequence similarity to the oil (D16S_41, DUni_17, DUni_102) and hydrocarbon (DUni_3, DUni_9, DUni_18, DUni_22, DUni_54, DUni_61, DUni_62, DUni_67, DUni_68, DUni_69, DUni_77, DUni_84, DUni_90, DUni_103, DUni_109, and DUni_110) degrading bacterial populations reported in different soil system [GenBank description, [31-33]]. Three sequence types (D16S_89, D16S_145 and DUni_83) have shown similarity to previously extracted sequences from the heavy metal contaminated soil or sediments [GenBank description, [34]]. Previous studies on Sundarban region revealed the contamination of hydrocarbon, petroleum and heavy metals in the soil $[16,35-38]$. The microbial 
Table 1 Summary of the 165 rRNA gene sequences identified in the D16S_pMOS and DUni_pMOS clone libraries

\begin{tabular}{|c|c|c|c|c|c|}
\hline Bacterial division & $\begin{array}{c}\text { Number of } \\
\text { sequence } \\
\text { types }\end{array}$ & $\begin{array}{l}\text { Number of sequence types } \\
\text { in D16S_pMOS library (\%) }\end{array}$ & $\begin{array}{l}\text { Number of sequence types } \\
\text { in DUni_pMOS library (\%) }\end{array}$ & $\begin{array}{c}\text { Number of } \\
\text { total clones } \\
(\%)\end{array}$ & $\begin{array}{l}\text { Sequence similarity to } \\
\text { the closest relatives }{ }^{\mathrm{C}}(\%)\end{array}$ \\
\hline Proteobacteria & 86 & $29(58 \%)^{a}$ & $57(71 \%)^{a}$ & 66.1 & $83-100$ \\
\hline Alpha & 6 & $1(3.5 \%)^{b}$ & $5(8.7 \%)^{b}$ & 4.6 & $87-96$ \\
\hline$\overline{\text { Beta }}$ & 7 & $4(14 \%)^{b}$ & $3(5.2 \%)^{b}$ & 5.4 & $92-99$ \\
\hline$\overline{\text { Gamma }}$ & 61 & $17(59 \%)^{b}$ & $44(77 \%)^{b}$ & 47 & $86-100$ \\
\hline Delta & 10 & $6(21 \%)^{b}$ & $4(7 \%)^{b}$ & 7.7 & 83-99 \\
\hline $\begin{array}{l}\text { Unassigned } \\
\text { proteobacteria }\end{array}$ & 2 & $1(2 \%)^{b}$ & $1(1.25 \%)^{b}$ & 1.5 & $91-94$ \\
\hline CFB group & 1 & $1(2 \%)^{a}$ & 0 & 0.8 & 93 \\
\hline Actinobacteria & 2 & 0 & $2(2.5 \%)^{a}$ & 1.53 & $87-98$ \\
\hline Planctomycetes & 4 & $2(4 \%)^{a}$ & $2(2.5 \%)^{a}$ & 3 & $86-92$ \\
\hline Firmicutes & 1 & $1(2 \%)^{a}$ & 0 & 0.8 & 92 \\
\hline Chloroflexi & 2 & 0 & $2(2.5 \%)^{a}$ & 1.53 & $89-98$ \\
\hline Gemmatimonadates & 2 & $1(2 \%)^{a}$ & $1(1.25 \%)^{a}$ & 0.75 & $94-96$ \\
\hline Acidobacteria & 1 & 0 & $1(1.25 \%)^{a}$ & 0.8 & 91 \\
\hline Marie eubacterium & 1 & $1(2 \%)^{\mathrm{a}}$ & 0 & 0.8 & 89 \\
\hline $\begin{array}{l}\text { Bacterial candidate } \\
\text { division OP8 }\end{array}$ & 1 & 0 & $1(1.25 \%)^{\mathrm{a}}$ & 0.8 & 87 \\
\hline Uncultured & 24 & $11(22 \%)^{a}$ & $13(16 \%)^{a}$ & 18.5 & $86-99$ \\
\hline Unidentified & 5 & $4(8 \%)^{a}$ & $1(1.25 \%)^{a}$ & 3.9 & $91-98$ \\
\hline Total & 130 & 50 & 80 & - & $83-100$ \\
\hline
\end{tabular}

"a" \% of clones among all the 130 clones selected from D16S_pMOS and DUni_pMOS libraries

"b" \% of clones among the proteobacterial clones under respective library

"c" Closest relatives as determined by the BLAST analysis

composition further indicates the previous observations and a probable possibility of bio-conversion of those contaminating substances in this soil area.

\section{Betaproteobacteria}

$14 \%$ and $5 \%$ of the proteobacterial sequence types were found to be betaproteobacterial from D16S_pMOS and DUni_pMOS libraries respectively (Table 1 ). In the D16S_pMOS library, the predominating clone (D16S_105) (three clones in the library) displayed a sequence similarity of $96 \%$ to its closest relative Amb_16S_1138, a betaproteobacterial clone previously recovered from trembling aspen [GenBank description]. In the DUni_pMOS library, among all the clones, DUni_99 showed 97\% similarity to an uncultured betaproteobacterial clone OS-C27, recovered from the abandoned semiarid lead-Zn mine tailing site [GenBank description, [39]]; DUni_62 showed 92\% similarity to D12-21, a betaproteobacterial clone recovered from a tar oil contaminated plume [GenBank description]; and finally the third clone DUni_104 showed 97\% similarity to Burkholderia cepacia strain Y1 isolated from oil polluted soil.

\section{Alphaproteobacteria}

The six alphaproteobacterial sequence types detected in the two libraries comprised $3.5 \%$ and $8.7 \%$ of the total proteobacterial sequence types in D16S_pMOS and DUni_pMOS respectively (Table 1). In the D16S_pMOS library, the clone D16S_119 was the only sequence type and that showed 95\% similarity to MPCa6_A10, an alphaproteobacterial clone recovered from wild and captive sponge Microciona prolifera in the Chesapeake Bay [GenBank description]. Five different alphaproteobacterial clones were obtained in DUni_pMOS library. The most predominating sequence type was DUni_6, which showed $87 \%$ similarity to MERTZ_OCM_210, an alphaproteobacterial clone reported within the Antarctic continental shelf sediment [GenBank description]. Among the other clones, sequence similarity revealed that they have shown identity to clones from the Seafloor Basalts from East Pacific Rise and the Juan de Fuca Ridge (DUni_42), industrial waste water treatment plants (DUni_56, DUni_57) [40] and Pedomicrobium fusiform DSM 5304 (DUni_105) [GenBank description, [41]].

\section{Deltaproteobacteria}

$2.1 \%$ and $7 \%$ of the cloned sequence types have shown similarity to the deltaproteobacterial sequences in the database from D16S_pMOS and DUni_pMOS libraries, respectively (Table 1). In the D16S_pMOS library, all the deltaproteobacterial clones showed identity to organisms or clones recently described in Mangrove 


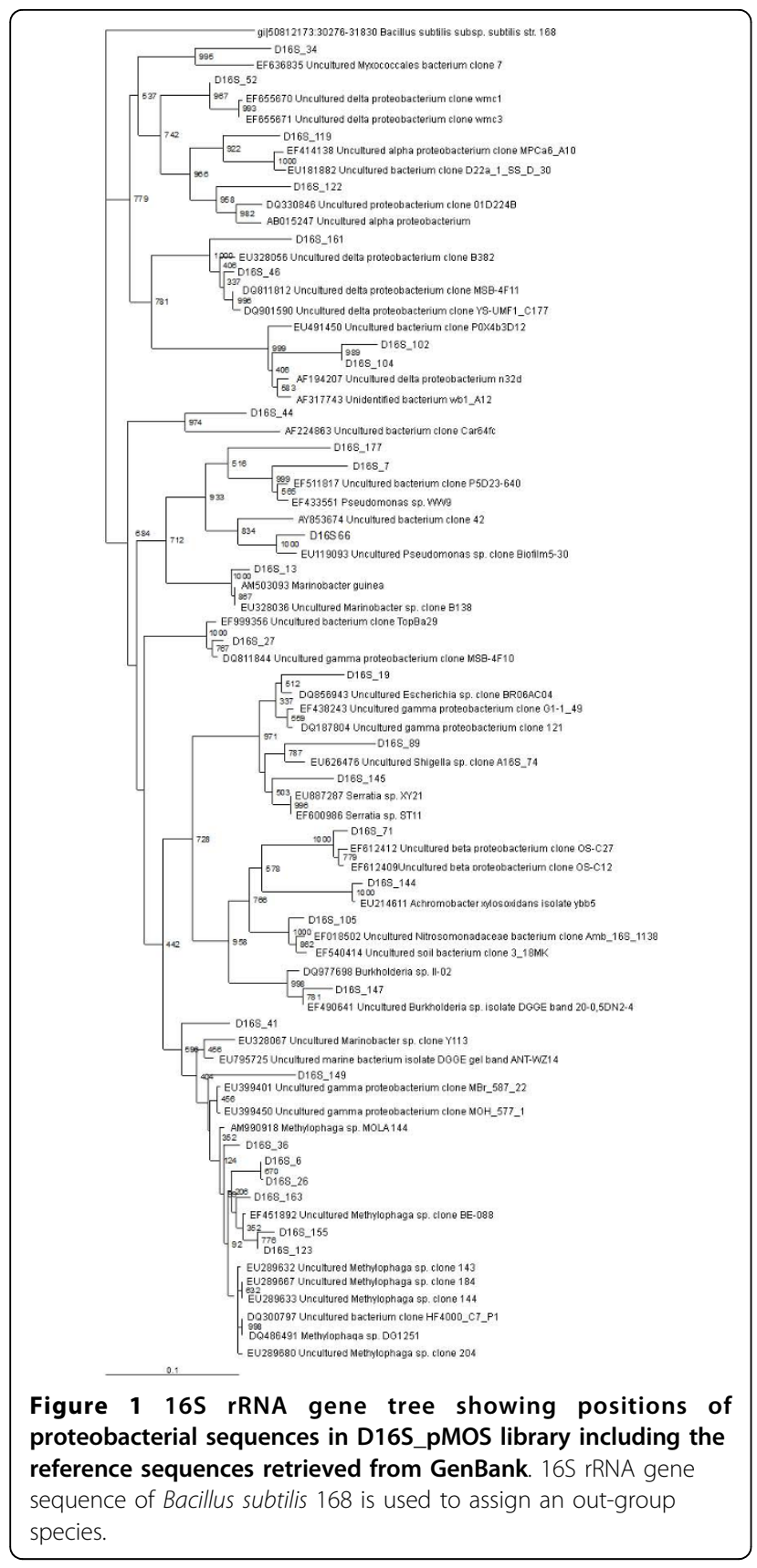

sediments. The sequence type D16S_52 was found to show $99 \%$ similarity with sulphate reducing bacterial strains [GenBank description]. In the DUni_pMOS library, clones DUni_79 and DUni_91 showed similarity with Desulfosarcina spp. and Desulfuromonas spp. respectively. These genera members have well-known metabolic features and involved in maintenance of S-cycle in soil. Probably the deltaproteobacterial strains in Sundarban sediments are largely involved in contributing towards the maintenance of sulphur cycle by sulphate reduction.
In addition to defined identities, two clones each from the D16S_pMOS and DUni_pMOS libraries showed only their proteobacterial identity. The clone D16S_122 showed similarity to uncultured proteobacterial clone 01D224B, which was described previously in the Guerrero Negro hyper saline microbial mat [GenBank description]. The clone DUni_55 showed identity to uncultured proteobacterial clone SIMO-1762, recovered from the salt marsh [GenBank description].

In both the libraries, many of the proteobacterial sequence types were found to show phylogenetic similarity with the strains (isolates) or clones recently described in marine sediments and waters, and were involved in S- or N-cycles, e.g., Methylophaga spp. DMS044, Methylophaga spp. DMS048, Uncultured gammaproteobacterium Y189 [42], Uncultured deltaproteobacterium wmc3 [GenBank description, EF655671], Uncultured Nitrosomonadaceae clone Amb_16S_1138 [GenBank description, EF018502], Uncultured Desulfuromonas spp. clone Lupin-1130-1-MDA-dsm3 [GenBank description, EF205265]. A large number of sequence types were also found to be phylogenetically similar to oil degradation associated microbes, e.g., Uncultured Marinobacter spp. Clone Y113 [GenBank description, EU328067], Uncultured gammaproteobacterium clone Y168 [GenBank description, EU328083]. There was also clone (DUni_67) identical to previously identified PAH degrading bacterial isolates [GenBank description]. Moreover in our libraries, we found many 16S rRNA gene sequences (D16S_6, D16S_66, D16S_89, D16S_106, D16S_123, D16S_134, D16S_155, D16S_163, DUni_4, DUni_19, DUni_45, DUni_65, and DUni_100) were similar to metagenomic clones or isolates reported in other studies from India [GenBank description, [7]]. In Sundarban sediment, compounds like polybrominated diphenyl ether (PBDE) and other hydrocarbons have been reported by different groups [35,36,38]. Moreover, in this sediment high concentration of heavy metal has been reported previously [37]. Furthermore, there are reports on the isolation of oil (petroleum) degrading bacterial strains from Sundarban sediment [16]. All this analytical and microbiological evidences further support our findings of different bacterial species related to bacterial clones or strains previously reported in hydrocarbon, oil, and heavy metal contaminated soils and sediments.

\section{Cytophaga-Flexibacteria-Bacteriodes}

A single sequence type, representing a total of six clones and accounting for $2 \%$ of the D16S_pMOS library, was found to cluster with the CFB group (Table 1) (Figure 2). The representing clone D16S_176 showed similarity with the Flexibacteraceae, bacterium recently reported from Venice Lagoon anoxic sediments [GenBank 


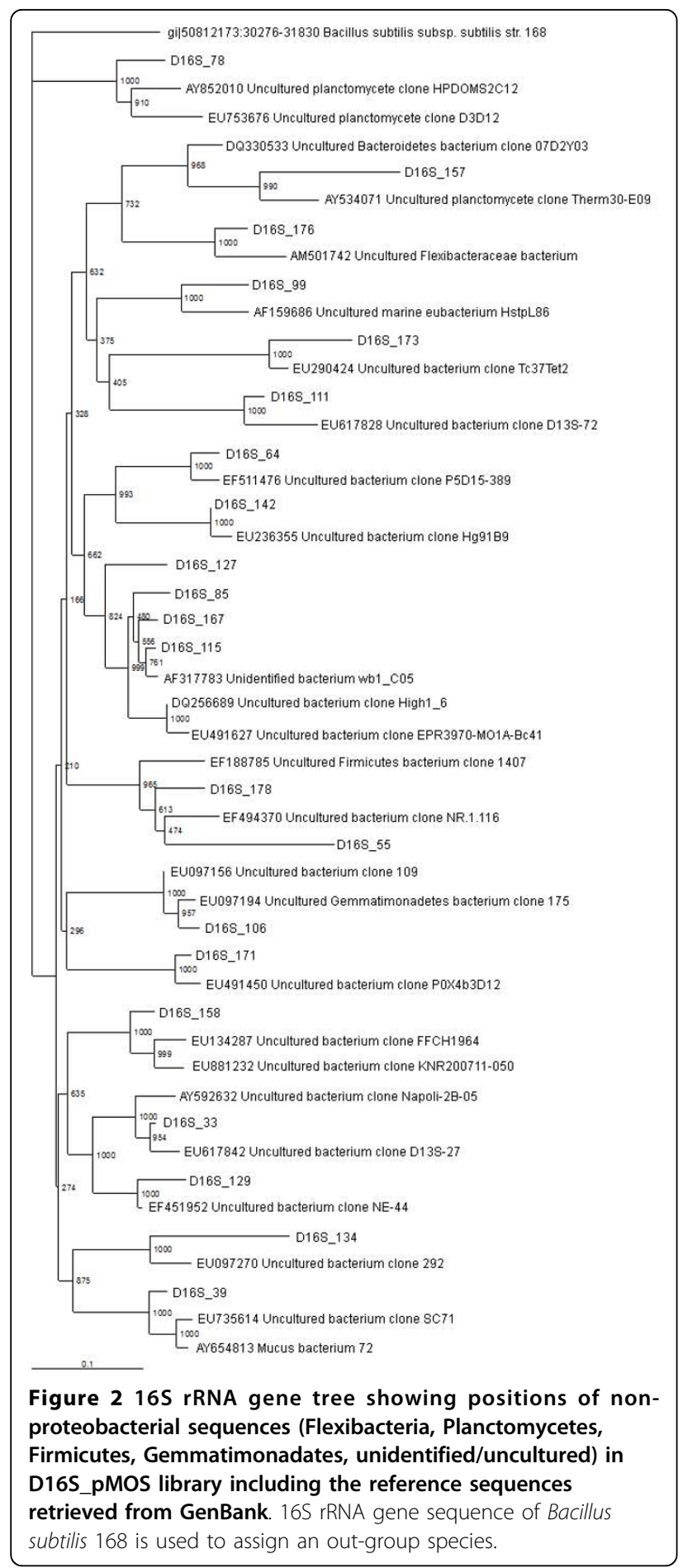

description]. No clone related to the CFB group was detected in DUni_pMOS library.

\section{Chloroflexi}

Two clones in DUni_pMOS library showed similarity with the Chloroflexi (Table 1) (Figure 4). The clone DUni_5 showed sequence similarity with A251, an uncultured Chloroflexi [GenBank description]. Another clone DUni_8 showed similarity with XME3, an uncultured Chloroflexi, recently reported in mangrove sediment of Xiamen, China [GenBank description].

\section{Planctomycetes}

Two sequence types, representing 6 clones in D16S_pMOS library and two sequence types, representing 3 clones in DUni_pMOS library, were found to group within the Planctomycetes (Table 1) (Figures 2 and 4). In D16S_pMOS library, the clone D16S_78 showed similarity to D3D12, an uncultured planctomycete clone recovered from the fresh water stromatolites from the Ruidera Pools Natural Park, Spain [GenBank description]. The clone D16S_157 was found to be identical to Therm30-E09, an uncultured planctomycete clone reported in the sediment of the Eastern Mediterranean Sea [12]. In DUni_pMOS library, the clone DUni_112 showed similarity to TAA-10-04, an uncultured Planctomycete clone recovered as the phage associated bacterium and the clone DUni_11 was found to show similarity with HCM3MC91_7C_FL, the planctomycete clone recovered from Eastern Mediterranean Sea [GenBank description].

\section{Other bacterial lineages}

A total of six clones, represented by two sequence types and accounted for $2.5 \%$ of the DUni_pMOS library were found to group within the Actinobacteria (Table 1). Two representative sequence types, DUni_64 and DUni_73 showed similarities with uncultured actinobacteria clone MERTZ_21CM_395 [43] and uncultured actinobacterial clone AT-s3-3 [43], respectively (Figures 2 and 4).

Two clones each from the two libraries were grouped within the Gemmatimonadetes (Table 1), a recently discovered bacterial phylum [44]. The clone D16S_106 showed 96\% similarity to Gemmatimonadetes bacterial clone 175, recovered from soil sample from radish rich area of Jaunpur, Uttarpradesh, India [GenBank description]. The other clone DUni_23 was found to be $94 \%$ identical to Gemmatimonadetes bacterial clone BolB1, reported recently as a member of phylogenetic division OP11 [45].

A single clone, DUni_38 was found to be identical to recently reported uncultured candidate division OP8 [GenBank description, [46]]. A single clone, D16S_178 was found to show similarity with the uncultured Firmicutes bacterium clone 1407, which was previously reported in the Altamira Cave [GenBank description]. Among the clones in the libraries, the clone DUni_13 showed similarity to HCM3MC83_3C-FL, an Acidobacterium spp. clone recently recovered from the sediment of Eastern Mediterranean Sea [GenBank description]. 


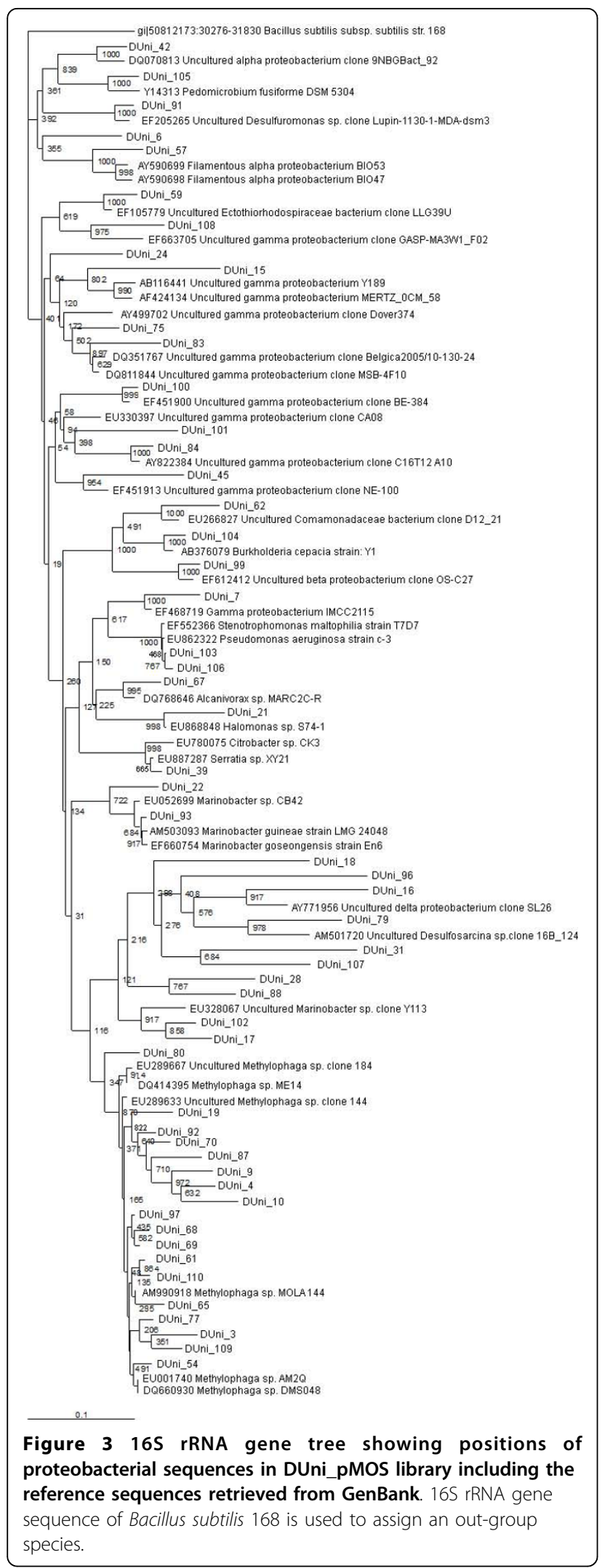

Other than known bacterial taxa, $22 \%$ and $16 \%$ of the clones from D16S_pMOS and DUni_pMOS libraries [26], were clustered within uncultured bacterial group (Table 1) (Figures 2 and 4). Most of the related uncultured bacterial clones from the blast search analysis revealed that they were reported from either marine sediments or from sea waters. In our library of clones, we also detected unidentified bacterial strains (four in D16S_pMOS and one in DUni_pMOS libraries). The only clone, D16S_99 showed identity to marine eubacterium HstpL86, previously described in the leaves of sea grass Halophila stipulacea.

\section{Conclusions}

In the present study, $16 \mathrm{~S}$ rRNA gene clone library based analysis was performed on the world's largest mangrove ecosystem, Sundarban sediment, for the first time. Even no culture based analysis of the bacterial community is yet reported from this mangrove ecosystem. The present analysis revealed that the Sundarban sediment possesses diverse bacterial population. At least 8 major phyla of the bacterial domain were detected in this sediment. Previous studies on bacterial diversity analysis reported five to thirteen major lineages in sediments collected from a variety of coastal marine environments $[3,15,24,25,42]$.

Sequencing analysis of the clones revealed the dominance of gammaproteobacterial sequences in both the libraries. Majority of the gammaproteobacterial clones resembled sequences recovered from oil and hydrocarbon rich marine sediments. This probably goes with the previous reports on Sundarban sediment where people have shown that in this sediment different hydrocarbons are present at high concentrations [35,36,38]. Moreover, a number of cultivable bacterial strains, which were capable of degrading petroleum, have been isolated from this sediment [16].

In the present report, a number of gammaproteobacterial clones were found to show similarity towards bacterial clones or isolates involved in sulfur cycling. Similar results were reported previously [42], while analysing coastal marine sediment beneath area of intensive shellfish aquaculture. Sulfur-oxidising bacterial strains are found to play an important role in detoxification of sulphide in marine sediments. Sulfur-reducing bacterial community instead is important in organic carbon oxidation in marine sediments and this observation is supported by the fact that sulphate is one of the main electron acceptors present in these environments. A number of gammaproteobacteria in the present study were found to show similarity to isolates or clones related to bioconversion of S-containing organic molecules (S-oxidisers). This interesting observation is supported by recent investigations, where it has been 


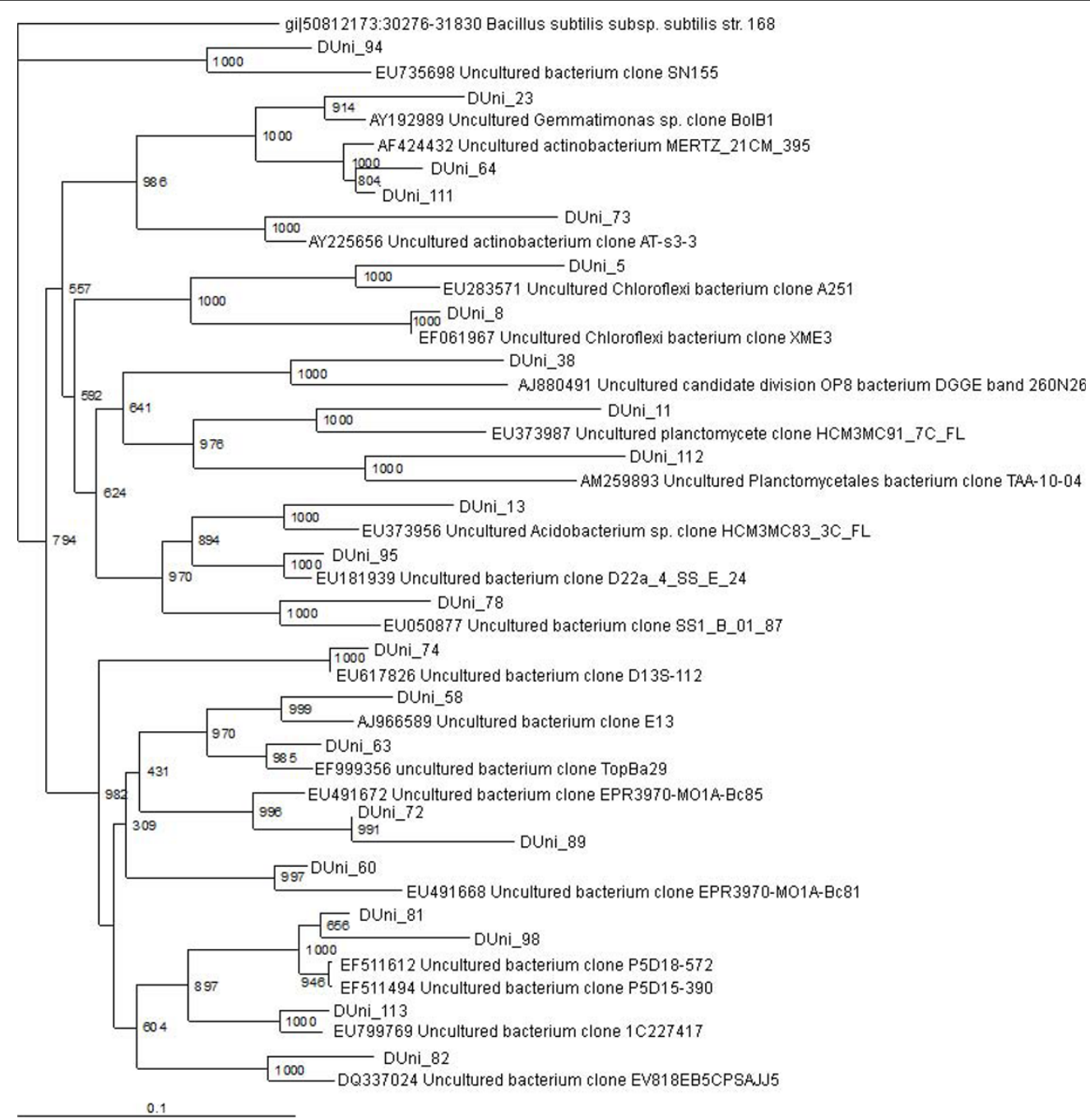

Figure 4 16S rRNA gene tree showing positions of non-proteobacterial sequences (Actinobacteria, Planctomycetes, Chloroflexi, Acidobacteria, Gemmatimonadates, unidentified/uncultured) in D16S_pMOS library including the reference sequences retrieved from GenBank. 16S rRNA gene sequence of Bacillus subtilis 168 is used to assign an out-group species.

shown that the reduction of sulphate may be an important pathway of organic matter mineralization in organic rich deposits typical of mangrove forests. Furthermore, most of the identified deltaproteobacterial clones from the two libraries showed similarity to the sulfur and sulphate reducing bacteria recovered from a variety of marine sediments. Analysis of only 130 clones might not be enough to cover the whole picture of S-cycle but it could provide a little insight about what is happening in Sundarban sediment. In marine ecosystems, S-cycle has proved to be the important biogeochemical factor that dictates the flow of electrons along the biological systems under such an anaerobic condition. Identification of sulfur- oxidising and sulphur and sulphate reducing bacterial clones refer to the anaerobic condition in this sediment and a possible maintenance of the biogeochemical cycle in Sundarban sediment.

The evidence of the presence of hydrocarbons $[35,36,38]$ in this sediment supports the finding of a comparatively lower number of alphaproteobacterial clones in Sundarban sediment. The special difference in the productivity of the water columns is probably enhances the reason for this observation in this sediment. Previous observations of Horner-devine et.al., 2003 [47] showed the dependence of alphaproteobacteria richness on the productivity levels in aquatic ecosystem. Furthermore, identification of the clones associated with hydrocarbon/oil degradation probably confirms the reason for the lower abundance of alphaproteobacteria in Sundarban sediment. 
In our study, epsilonproteobacteria are absent in both the libraries. It has been well documented that epsilonproteobacteria were absent or scarce in other clone libraries of coastal marine sediments [3,15,42]. Although, some reports have described the presence of epsilonbacteria in the library of clones made from marine sediments $[24,48]$.

Identification of Gemmatimonades in our clone libraries was interesting and probably the first report of recovery of this phylum from mangrove sediment.

In conclusion, the Sundarban surface sediment harboured a phylogenetically diverse population of organisms from bacterial domain. At least 8 major phyla have been recovered from Sundarban sediment. The proteobacteria, especially the gammaproteobacteria were found to be abundant in both the libraries. While some of the 16S rRNA gene sequence types detected were related to genera or taxa that were classically identified in Sundarban sediment and correlated to a defined functional arena; many were derived from uncultured/unidentified taxa. Previous studies have shown that the primer pair uni-for/uni-rev was good for proteobacteria. As in marine system, proteobacterial communities are major; this pair of primers was employed in the present study. Further studies are necessary to understand the bacterial diversity in more details. This is the first report describing the bacterial diversity in Sundarban sediment. We feel that the present study has obtained a fundamental insight into the major bacterial populations in Sundarban sediment. This study will definitely open a new era in understanding the microbial diversity in Sundarban.

\begin{abstract}
Acknowledgements
This study was supported by a grant from the Centre for Advance Studies (CAS) programme of the Department of Biochemistry, University Grants Commission, India. Support for DNA sequencing was obtained from the NCMP grant to University of Calcutta, India. A research fellowship for AG was provided by the B. C. Guha Endowment Fund, University of Calcutta, India.
\end{abstract}

\section{Author details \\ ${ }^{1}$ Department of Biochemistry and Department of Biotechnology, University of Calcutta, 35, Ballygunge Circular Road, Kolkata- 700019, West Bengal, India ${ }^{2}$ Department of Agricultural Chemistry \& Soil Science, Institute of Agricultural Science, University of Calcutta, 35, Ballygunge Circular Road. Kolkata- 700019, West Bengal, India. ${ }^{3}$ Current address: Max Planck Research Group "Molecular Biology of Archaea", Max Planck Institute for Terrestrial Microbiology, Karl- von-Frisch-Strasse, D-35043 Marburg, Germany. ${ }^{4}$ Current address: Division of Nephrology Department of Medicine, 7703 Floyd Curl Drive, University of Texas Health Science Center at San Antonio, San Antonio, Texas 78229 3900, USA. ${ }^{5}$ Current address: Institute of Molecular Cancer Research, University of Zurich, 17 K 28, Winterthurerstrasse 190, Zurich-8057, Switzerland.}

\section{Authors' contributions}

AG designed and conducted the experiments in consultation with DJC, analyzed the data and drafted the manuscript. ND helped with the library constructions, screening and sequencing analysis. $A B$ participated in sequencing analysis, sequence alignment and phylogenetic analysis. AT helped with the screening of the libraries and sequence alignment. SB helped with the screening of the libraries. KC helped with the sampling, soil analyses and interpretation. DJC was involved in the acquisition of funding, contributed to the concept, experimental design, analysis of the data and revising the manuscript. All authors read and approved the final manuscript.

\section{Competing interests}

The authors declare that they have no competing interests.

Received: 29 June 2009

Accepted: 17 February 2010 Published: 17 February 2010

\section{References}

1. Amann Rl, Ludwig W, Schleifer KH: Phylogenetic identification and in situ detection of individual microbial cells without cultivation. Microbiol Rev 1995, 59:143-169.

2. Torsvik V, Goksoyr J, Daae FL: High diversity in DNA of soil bacteria. Appl Environ Microbiol 1990, 56:782-787.

3. Gray JP, Herwig RP: Phylogenetic analysis of the bacterial communities in marine sediments. Appl Environ Microbiol 1996, 62:4049-4059.

4. Alongi DM, Christoffersen P, Tirendi F: The influence of forest type on microbial-nutrient relationships in tropical mangrove sediments. J Exp Mar Biol Ecol 1993, 171:201-223

5. Holguin G, Guzman MA, Bashan Y: Two new nitrogen-fixing bacteria from the rhizosphere of mangrove trees: their isolation, identification and in vitro interaction with rhizosphere Staphylococcus sp. FEMS Microbiol Ecol 1992, 101:207-216.

6. Holguin $G$, Vazquez $P$, Bashan $Y$ : The role of sediment microorganisms in the productivity, conservation, and rehabilitation of mangrove ecosystems: an overview. Biol Fert Soils 2001, 33:265-278.

7. Sengupta A, Chaudhuri S: Ecology of heterotrophic dinitrogen fixation in the rhizosphere of mangrove plant community at the Ganges river estuary in India. Oecologia 1991, 87:560-564.

8. Vazquez P, Holguin G, Puente ME, Lopez-Cortes A, Bashan Y: Phosphatesolubilizing microorganisms associated with the rhizosphere of mangroves in a semiarid coastal lagoon. Biol Fertil Soils 2000, 30:460-468.

9. Holguin G, Bashan Y, Mendoza-Salgado RA, Amador E, Toledo G, Vazquez P, Amador A: La Microbiologia de los manglares. Bosques en la frontera entre el mar y la tierrra. Ciencia Desarrollo 1999, 144:26-35.

10. Alongi DM: Bacterial productivity and microbial biomass in tropical mangrove sediments. Microbiol Ecol 1988, 15:59-79.

11. Bano N, Nisa M-U, Khan N, Saleem M, Harrison PJ, Ahmed SI, Azam F: Significance of bacteria in the flux of organic matter in the tidal creeks of the mangrove ecosystem of the Indus river delta, Pakistan. Mar Ecol Prog Ser 1997, 157:1-12.

12. Polymenakou PN, Bertilsson S, Tselepides A, Stephanou EG: Bacterial community composition in different sediments from the Eastern Mediterranean Sea: a comparison of four $16 \mathrm{~S}$ ribosomal DNA clone libraries. Microb Ecol 2005, 50:447-462.

13. Ravenschlag K, Sahm K, Pernthaler J, Amann R: High bacterial diversity in permanently cold marine sediments. Appl Environ Microbiol 1999, 65:3982-3989.

14. Todorov JR, Chistoserdov AY, Aller JY: Molecular analysis of microbial communities in mobile deltaic muds of Southeastern Papua New Guinea. FEMS Microbiol Ecol 2000, 33:147-155.

15. Urakawa H, Kita-Tsukamoto K, Ohwada K: Microbial diversity in marine sediments from Sagami Bay and Tokyo Bay, Japan, as determined by 16S rRNA gene analysis. Microbiology 1999, 145:3305-3315.

16. Roy S, Hens D, Biswas D, Biswas D, Kumar R: Survey of petroleum degrading bacteria in coastal waters of Sunderban. Biosphere Reserve. World J Microbiol Biotech 2002, 18:575-581.

17. Gopal B, Chauhan M: Biodiversity and its conservation in the Sundarban Mangrove Ecosystem. Aquatic Sciences 2006, 69:338-354.

18. Staley JT, Gosink JJ: Poles apart: biodiversity and biogeography of sea ice bacteria. Annu Rev Microbiol 1999, 53:189-215.

19. Black CA: Methods of Soil Analysis. American Society of Agronomy, Wisconsin, USA 1965.

20. Nelson DW, Somers LE: Organic carbon. Methods in soil microbiology and biochemistry Academic, LondonAlef K, Nannipieri P 1975, 59-60.

21. Piper CS: Soil and Plant analysis. Maver Publishers, Bombay, India 1966.

22. Miller DN, Bryant JE, Madsen EL, Ghiorse WC: Evaluation and optimization of DNA extraction and purification procedures for soil and sediment samples. Appl Environ Microbiol 1999, 65:4715-4724. 
23. Lane DJ: 16S/23S rRNA sequencing. Nucleic acid techniques in bacterial systematics Wiley, New York, NYStackebrandt E, Goodfellow M 1991, 115-175.

24. Bowman JP, McCuaig RD: Biodiversity, community structural shifts, and biogeography of prokaryotes within Antarctic continental shelf sediment. Appl Environ Microbiol 2003, 69:2463-2483.

25. Cifuentes A, Anton J, Benlloch S, Donnelly A, Herbert RA, RodriguezValera F: Prokaryotic diversity in Zostera noltii-colonized marine sediments. Appl Environ Microbiol 2000, 66:1715-1719.

26. Holmes AJ, Tujula NA, Holley M, Contos A, James JM, Rogers P, Gillings MR: Phylogenetic structure of unusual aquatic microbial formations in Nullarbor caves, Australia. Environ Microbio/ 2001, 3:256-264.

27. Giovannoni SJ, Britschgi TB, Moyer CL, Field KG: Genetic diversity in Sargasso sea bacterioplancton. Nature 1990, 344:60-63.

28. Thompson JD, Gibson TJ, Plewniak F, Jeanmougin F, Higgins DG: The ClustalX windows interface: flexible strategies for multiple sequence alignment aided by quality analysis tools. Nucleic Acids Res 1997, 24:4876-4882.

29. Page RD: TreeView: an application to display phylogenetic trees on personal computers. Comput Appl Biosci 1996, 12:357-358.

30. Falsenstein J: Condence limits on phylogenetics: an approach using bootstrap. Evolution 1985, 39:783-791.

31. Bissett A, Bowman J, Burke C: Bacterial diversity in organically-enriched fish farm sediments. FEMS Microbiol Ecol 2006, 55:48-56.

32. Neufeld JD, Schafer H, Cox MJ, Boden R, McDonald IR, Murrell JC: Stableisotope probing implicates Methylophaga spp and novel Gammaproteobacteria in marine methanol and methylamine metabolism. Isme J 2007, 1:480-491.

33. Schafer $\mathrm{H}$ : Isolation of Methylophaga spp. from marine dimethylsulfidedegrading enrichment cultures and identification of polypeptides induced during growth on dimethylsulfide. Appl Environ Microbiol 2007, 73:2580-2591.

34. Gillan DC, Pernet P: Adherent bacteria in heavy metal contaminated marine sediments. Biofouling 2007, 23:1-13.

35. Binelli A, Sarkar SK, Chatterjee M, Riva C, Parolini M, Bhattacharya BD, Bhattacharya AK, Satpathy KK: Concentration of polybrominated diphenyl ethers (PBDEs) in sediment cores of Sundarban mangrove wetland, northeastern part of Bay of Bengal (India). Mar Pollut Bull 2007, 54:1220-1229.

36. Binelli A, Sarkar SK, Chatterjee M, Riva C, Parolini M, Bhattacharya B, Bhattacharya AK, Satpathy KK: A comparison of sediment quality guidelines for toxicity assessment in the Sunderban wetlands (Bay of Bengal, India). Chemosphere 2008, 73:1129-1137.

37. Saha M, Cobelo-Garcia A, Sarkar SK, Prego R, Bhattacharya B: Distribution of metals in representative biota of sundarban mangrove wetland, northeast India. Bull Environ Contam Toxicol 2006, 76:656-662.

38. Sahu LK, Lal S, Venkataramani S: Distributions of $\mathrm{O}_{3}, \mathrm{CO}$ and hydrocarbons over the Bay of Bengal: A study to assess the role of transport from southern India and marine regions during September-October 2002. Atmospheric Environment 2006, 40:4633-4645.

39. Mendez MO, Neilson JW, Maier RM: Characterization of a bacterial community in an abandoned semiarid lead-zinc mine tailing site. Appl Environ Microbiol 2008, 74:3899-3907.

40. Levantesi C, Beimfohr C, Geurkink B, Rossetti S, Thelen K, Krooneman J, Snaidr J, Waarde van der J, Tandoi V: Filamentous Alphaproteobacteria associated with bulking in industrial wastewater treatment plants. Syst Appl Microbiol 2004, 27:716-727.

41. Rainey FA, Ward-Rainey N, Gliesche CG, Stackebrandt E: Phylogenetic analysis and intrageneric structure of the genus Hyphomicrobium and the related genus Filomicrobium. Int J Syst Bacteriol 1998, 48(Pt 3):635-639.

42. Asami $H$, Aida M, Watanabe $K$ : Accelerated sulfur cycle in coastal marine sediment beneath areas of intensive shellfish aquaculture. Appl Environ Microbiol 2005, 71:2925-2933.

43. Lopez-Garcia P, Duperron S, Philippot P, Foriel J, Susini J, Moreira D: Bacterial diversity in hydrothermal sediment and epsilonproteobacteria dominance in experimental microcolonizers at the Mid-Atlantic Ridge. Environ Microbiol 2003, 5:961-976.

44. Zhang H, Sekiguchi $Y$, Hanada S, Hugenholtz P, Kim H, Kamagata Y, Nakamura K: Gemmatimonas aurantiaca gen. nov., sp. nov., a gramnegative, aerobic, polyphosphate-accumulating micro-organism, the first cultured representative of the new bacterial phylum Gemmatimonadetes phyl. nov. Int J Syst Evol Microbiol 2003, 53(Pt 4):1155-1163.

45. Harris JK, Kelley ST, Pace NR: New perspective on uncultured bacterial phylogenetic division OP11. Appl Environ Microbiol 2004, 70:845-849.

46. Wilms R, Köpke B, Sass H, Chang TS, Cypionka H, Engelen B: Deep biosphere-related bacteria within the subsurface of tidal flat sediments. Environ Microbiol 2006, 8:709-719.

47. Horner-Devine MC, Leibold MA, Smith VH, Bohannan BJM: Bacterial diversity patterns along a gradient of primary productivity. Ecol Lett 2003, 6:613-622.

48. Liang JB, Chen YQ, Lan CY, Tam NFY, Zan QJ, Huang LN: Recovery of novel bacterial diversity from mangrove sediment. Mar Biol 2007, 150:739-747.

doi:10.1186/1746-1448-6-1

Cite this article as: Ghosh et al:: Culture independent molecular analysis of bacterial communities in the mangrove sediment of Sundarban, India. Saline Systems 2010 6:1.

\section{Submit your next manuscript to BioMed Central and take full advantage of:}

- Convenient online submission

- Thorough peer review

- No space constraints or color figure charges

- Immediate publication on acceptance

- Inclusion in PubMed, CAS, Scopus and Google Scholar

- Research which is freely available for redistribution 